\title{
Conhecimento dos cirurgiões-dentistas da capital de um estado do nordeste brasileiro sobre a utilização de agentes químicos como coadjuvantes na terapia periodontal
}

Knowledge of dentists in the capital of a northeastern Brazilian state on the use of chemical agents as adjuvants in periodontal therapy

Conocimiento de odontólogos de la capital de un estado del noreste de Brasil sobre el uso de agentes químicos como adyuvantes en la terapia periodontal

Recebido: 09/07/2021 | Revisado: 17/07/2021 | Aceito: 21/07/2021 | Publicado: 29/07/2021

Kattyélen Luzyane de Farias ORCID: https://orcid.org/0000-0002-0923-7966 Centro Universitário Cesmac, Brasil E-mail: kattyelen@hotmail.com Maylla Albina dos Santos ORCID: https://orcid.org/0000-0002-2511-5010 Centro Universitário Cesmac, Brasil E-mail: maylla-albina@hotmail.com Danielly Melo Gomes ORCID: https://orcid.org/0000-0002-9113-368X Centro Universitário Cesmac, Brasil

E-mail: daniellycaetano15@hotmail.com Jessika Nathalia Victor Lucas ORCID: https://orcid.org/0000-0003-1220-2868 Centro Universitário Cesmac, Brasil E-mail:jessikavictor@hotmail.com

Wanderson Thalles de Souza Braga ORCID: https://orcid.org/0000-0003-3617-3950 Centro Universitário Tiradentes, Brasil

E-mail: wanderson.thalles@souunit.com.br Arianne Kimberly Barbosa da Matta ORCID: https://orcid.org/0000-0003-0039-9560 Centro Universitário Tiradentes, Brasil

E-mail: arianne.kimberly@ souunit.com.br Natália Karol de Andrade ORCID: https://orcid.org/0000-0001-8809-8660 Centro Universitário Cesmac, Brasil

E-mail: karol.andrade.odonto@hotmail.com

\begin{abstract}
Resumo
Introdução: O biofilme dental é formado pela fixação e proliferação de bactérias na película adquirida existente nas superfícies dos dentes e existe uma relação direta entre o nível de higiene oral, quantidade/qualidade desse biofilme e a prevalência da doença periodontal e sua gravidade. Contudo, a imperícia da escovação adequada conduziu à procura de agentes químicos que aperfeiçoassem o controle do biofilme. Objetivos: Investigar o grau de conhecimento dos cirurgiões-dentistas acerca do uso desses agentes como coadjuvantes na terapia periodontal. Metodologia: Foi aplicado um questionário com 164 cirurgiões-dentistas da capital de um estado do nordeste brasileiro, contendo perguntas como: idade, gênero, grau acadêmico, especialidade, área de atuação, forma de atualização profissional e perguntas sobre agentes químicos prescritos tanto na forma de dentifrício como de enxaguatórios bucais. Resultados: A Clorexidina foi a preferência de grande parte dos entrevistados quanto aos enxaguatórios e Triclosan e Citrato de Zinco foram as substâncias mais escolhidas quanto aos dentifrícios. Conclusão: O conhecimento acerca dos agentes químicos como coadjuvantes na terapia periodontal por parte dos cirurgiões-dentistas se mostrou limitado, o que pode implicar em prescrições incorretas.
\end{abstract}

Palavras-chave: Doenças periodontais; Antissépticos bucais. Higiene bucal; Conhecimento.

\begin{abstract}
Introduction: Dental biofilm is formed by the fixation and proliferation of bacteria in the acquired film existing on tooth surfaces and there is a direct relationship between the level of oral hygiene, quantity/quality of this biofilm and the prevalence of periodontal disease and its severity. However, the lack of proper brushing led to the search for chemical agents that would improve biofilm control. Objectives: To investigate the degree of knowledge of dentists about the use
\end{abstract}


of these agents as adjuncts in periodontal therapy. Methodology: A questionnaire was applied to 164 dentists from the capital of a northeastern Brazilian state, containing questions such as: age, gender, academic degree, specialty, area of expertise, form of professional updating and questions about chemical agents prescribed both in form of toothpaste and mouthwash. Results: Chlorhexidine was the preference of most respondents as for mouthwashes and Triclosan and Zinc Citrate were the most chosen substances for toothpastes. Conclusion: The knowledge about chemical agents as adjuvants in periodontal therapy by dentists proved to be limited, which may lead to incorrect prescriptions.

Keywords: Periodontal diseases; Mouthwashes; Oral hygiene; Knowledge.

\section{Resumen}

Introducción: El biofilm dental está formado por la fijación y proliferación de bacterias en el film adquirido existente en la superficie de los dientes y existe una relación directa entre el nivel de higiene bucal, la cantidad / calidad de este biofilm y la prevalencia de la enfermedad periodontal y su gravedad. Sin embargo, la falta de un cepillado adecuado llevó a la búsqueda de agentes químicos que mejoran el control de la biopelícula. Objetivos: Investigar el grado de conocimiento de los dentistas sobre el uso de estos agentes como coadyuvantes en la terapia periodontal. Metodología: Se aplicó un cuestionario a 164 odontólogos de la capital de un estado nororiental brasileño, que contenía preguntas como: edad, género, grado académico, especialidad, área de especialización, forma de actualización profesional y preguntas sobre agentes químicos prescritos tanto en formar pasta de dientes y enjuague bucal. Resultados: La clorhexidina fue la preferencia de la mayoría de los encuestados en cuanto a enjuagues bucales y el triclosán y el citrato de zinc fueron las sustancias más elegidas para las pastas dentales. Conclusión: El conocimiento sobre agentes químicos como adyuvantes en la terapia periodontal por parte de los odontólogos resultó ser limitado, lo que puede conducir a prescripciones incorrectas.

Palabras clave: Enfermedades periodontales; Antisépticos bucales; Higiene bucal; Conocimiento.

\section{Introdução}

O biofilme dental é formado pela fixação de bactérias na película adquirida e a proliferação das mesmas nas superfícies dos dentes. Existe uma relação direta entre o nível de higiene oral, quantidade e qualidade do biofilme dentário e a prevalência da doença periodontal e sua gravidade (Filogônio, Soares, Horta, Penido \& Cruz, 2011).

A remoção mecânica do biofilme é um método eficaz de controle da inflamação gengival (Silva et al., 2021). No entanto, as técnicas eficientes de controle do biofilme requerem uma motivação especial e habilidades para seu ótimo uso. Contudo, a incapacidade da população adulta para realizar a escovação adequada conduziu a procura de agentes químicos para aperfeiçoarem o controle do biofilme, pois a utilização dessas substâncias também pode contribuir na desorganização do mesmo, assim como retardar a sua formação (Filogônio, Soares, Horta, Penido \& Cruz, 2011; Oliveira, Torres, Pereira, Mota \& Carlos, 2008).

Assim, o controle do biofilme bacteriano pode ser realizado por meios mecânicos, químicos (Silva et al., 2021) ou pela associação de ambos, especialmente em indivíduos com alto risco de desenvolver doenças bucais. Desta forma o uso de enxaguatórios bucais antissépticos e dentifrícios fazem parte de um regime de higiene oral completo (Pannuti et al., 2003; Amini, Araujo, Mei-miau, Charles \& Sharma, 2009; Tartaglia, Tadakamadla, Connelly, Sforza \& Martin, 2019).

$\mathrm{O}$ agente ideal deve ter alta capacidade de inibir a formação do biofilme dental, alto efeito antimicrobiano e alta substantividade e deve necessariamente causar redução da adesão bacteriana às superfícies dentárias e à mucosa oral, modificar o metabolismo bacteriano e modificar a ecologia do biofilme para favorecer o desenvolvimento de uma microflora oral menos patogênica (Araujo et al., 2012).

É importante que o cirurgião-dentista conheça bem as necessidades de seu paciente antes de prescrever um agente químico como coadjuvante no controle do biofilme dental, selecionando adequadamente o princípio ativo mais indicado para cada caso. Os veículos para administração de tais agentes vão desde a forma de dentifrícios, géis, dispositivos para depósitos como vernizes e enxaguatórios bucais (Carneiro et al., 2014). E tem como as substâncias mais utilizadas os Óleos Essenciais, Triclosan, Cloreto de Cetilpiridínio e Clorexidina Tartaglia, Tadakamadla, Connelly, Sforza \& Martin, 2019).

A atividade dos Óleos Essenciais (OEs) na inibição e redução do biofilme dentário deriva da adsorção ao esmalte dental que resulta na redução da deposição de biofilme dental. Bochechos contendo OEs induzem a uma profunda redução bacteriana em modelos de biofilme de laboratório quando comparado com outros bochechos como descrito no estudo randomizado de 
Charles e colaboradores (2011).

O Triclosan (TRI) retarda o crescimento descendente de biofilme do ambiente supra para o subgengival, e tem a vantagem conhecida da adsorção e liberação de agentes químicos no meio oral (Andrade, Weidlich, Angst, Gomes \& Oppermann, 2015). A metanálise feita por Gunsolley (2006) demonstrou que o copolímero gantrez é um elemento necessário para que o triclosan funcione de maneira adequada e com uma elevada substantividade

Outro agente químico disponível no mercado é o Cloreto de Cetilpiridínio (CCP) que é um agente antimicrobiano (Miranda et al., 2020) e que tem propriedades catiônicas que ajudam a manter sua substantividade, o ensaio randomizado de Amini, Araujo, Mei-miau, Charles e Sharma (2009) utilizando um modelo experimental de gengivite apresentou redução no índice de biofilme quando utiliza-se CCP 2x por dia durante 2 semanas.

A Clorexidina (CLX) é um dos produtos farmacêuticos mais amplamente utilizados para controlar o biofilme periodontopatogênico e a gengivite. Entre os enxaguatórios bucais, a CLX tem efeitos antibacterianos contra uma grande variedade de bactérias e é reconhecida como padrão-ouro para os agentes anti-biofilme (Cieplik, Jakubovics, Buchalla, Maisch, Hellwig \& Al-Ahmad, 2019). Os efeitos colaterais da CLX estão relacionados ao manchamento dos dentes (Miranda et al., 2020), materiais restauradores e dorso da língua, assim como na alteração do paladar, fatores esses que contraindicam o seu uso por longos períodos (Zarandia, Salahaddin \& Faramarzi, 2016; Tartaglia, Tadakamadla, Connelly, Sforza \& Martin, 2019).

Diante da importância do cirurgião-dentista compreender quais fatores levar em consideração no momento da prescrição de um agente químico na terapia periodontal, fez-se pertinente avaliar o nível de conhecimento dos mesmos sobre o uso desses agentes para que a partir dos dados coletados sejam traçadas estratégias que possam favorecer tanto o paciente como os cirurgiões-dentistas em geral, fazendo com que se tenha uma nova visão ou abordagem em relação à terapia periodontal.

Esta avaliação foi desenvolvida a partir da observação dos tipos de agentes químicos utilizados e da forma como foram prescritos, verificando assim se a prescrição foi adequada de acordo com as evidências científicas.

\section{Metodologia}

Este trabalho trata-se de um estudo observacional transversal e aprovado pelo Comitê de Ética em Pesquisa (Centro Universitário CESMAC - Maceió-AL / parecer 2.351.427), no qual foram recrutados 334 cirurgiões-dentistas independente do tempo de formação e da especialidade e que estavam devidamente registrados no Conselho Regional de Odontologia, não houve distinção quanto a idade, sexo, tempo de formação, bem como em relação ao local de trabalho, quer seja do serviço público ou em clínicas particulares. Essa amostra representa, portanto, 14,77\% do total de cirurgiões-dentistas de uma capital do nordeste brasileiro segundo dados fornecidos pelo CFO (Conselho Federal de Odontologia) em junho de 2017. O critério de inclusão foi que estariam aptos a participarem da pesquisa, cirurgiões-dentistas inscritos no CRO/AL atuantes em clínicas odontológicas da capital, onde consequentemente o critério de exclusão foi que cirurgiões-dentistas inscritos no CRO/AL que não atuavam na capital. Dos 334 cirurgiões-dentistas recrutados dentre eles, 97 se recusaram a participar da pesquisa e 73 não assinaram o termo de consentimento livre e esclarecido (TCLE), portanto foram excluídos da amostra que foi composta por 164 cirurgiões-dentistas.

Foi elaborado um questionário com 17 questões, todas pertinentes aos objetivos propostos no estudo, que foi entregue aos voluntários da pesquisa juntamente com o TCLE. Os cirurgiões-dentistas foram abordados através de seus e-mails que foram disponibilizados pelo $\mathrm{CRO} / \mathrm{AL}$, onde foi marcada uma visita em seu local de trabalho ou domicílio para que os dados da pesquisa fossem obtidos. O benefício em participar da pesquisa foi o recebimento de um folder contendo os principais agentes químicos, seus representantes comerciais, suas indicações, concentração e posologia. Após todos os indivíduos da pesquisa responderem o questionário os resultados foram tabulados e submetidos à análise estatística descritiva.

Para isto foi realizada uma análise de dados utilizando o software estatístico Statistical Package for the Social Sciences (SPSS) versão 20, onde com base numa amostra de 164 entrevistados, inicialmente traçou-se o perfil da amostra a partir do 
estudo das medidas descritivas das variáveis quantitativas e das frequências absolutas e percentuais das variáveis qualitativas, sendo então possível entender o comportamento da amostra em questão.

Para verificar a influência dos fatores grau acadêmico, área de atuação e tempo de formação nas respostas obtidas, verificou-se as frequências de acertos para cada categoria, bem como a aplicação do teste Qui-quadrado de Independência para avaliar uma possível associação entre estas variáveis (fator vs resposta). Sem fazer suposições teóricas sobre os parâmetros da distribuição, este teste avalia a hipótese nula de que as duas variáveis são independentes. A decisão deste teste se baseia no pvalor, onde definido o nível de $5 \%$ de significância (equivalente a 95\% de certeza), se p-valor $<0,05$ conclui-se que as variáveis não são independentes. Por outro lado, se p-valor $>0,05$ decide-se por considerar que as variáveis são independentes.

\section{Resultados}

Com base nas variáveis qualitativas, conforme descrito na Tabela 1, observou-se que 65,9\% dos entrevistados eram do sexo feminino e 34,1\% do sexo masculino, além disto, 46,3\% dos entrevistados tinham especialização, 39\% bacharelado, 9,8\% eram mestres e 4,9\% doutores. A maior parte dos entrevistados (26,2\%) afirmou possuir 11 a 20 anos de formação e em apenas $10,4 \%$ dos profissionais obteve-se o tempo de maior de 20 anos de formação, em relação às idades dos entrevistados, observouse uma média de 33,6 anos de idade com desvio padrão de 8,7 anos. Entre os diferentes tempos de formação dos entrevistados, obteve-se que de acordo com os resultados do teste Qui-Quadrado de Independência, o tempo de formação não está associado (p-valor >0,05) às respostas.

Tabela 1 - Distribuição dos entrevistados quanto ao Sexo, Grau Acadêmico, Tempo de Formação e medidas descritivas para a Idade.

\begin{tabular}{|c|c|c|c|}
\hline & & $\mathbf{n}$ & $\%$ \\
\hline \multirow[t]{2}{*}{ Sexo } & Feminino & 108 & $65,90 \%$ \\
\hline & Masculino & 56 & $34,10 \%$ \\
\hline \multirow[t]{4}{*}{ Grau Acadêmico } & Bacharel & 64 & $39 \%$ \\
\hline & Especialista & 76 & $46,30 \%$ \\
\hline & Mestre & 16 & $9,80 \%$ \\
\hline & Doutor & 8 & $4,90 \%$ \\
\hline \multirow[t]{5}{*}{ Tempo de Formação } & 11 a 20 anos & 43 & $26,2 \%$ \\
\hline & 3 a 5 anos & 37 & $22,6 \%$ \\
\hline & 0 a 2 anos & 36 & $22,0 \%$ \\
\hline & 6 a 10 anos & 31 & $18,9 \%$ \\
\hline & Mais de 20 anos & 17 & $10,4 \%$ \\
\hline \multirow[t]{5}{*}{ Idade } & Média & \multicolumn{2}{|c|}{33,6 anos } \\
\hline & Desvio padrão & \multicolumn{2}{|c|}{8,7 anos } \\
\hline & IC 95\% & \multicolumn{2}{|c|}{$[32.2 ; 34.9]$} \\
\hline & $\mathrm{CV}(\%)$ & \multicolumn{2}{|c|}{$25,8 \%$} \\
\hline & Mediana & \multicolumn{2}{|c|}{31,5 anos } \\
\hline
\end{tabular}

Fonte: Dados da pesquisa.

Com relação às especialidades citadas, observou-se que 63 entrevistados não tinham especialidade, porém dos 101 que citaram ter pelo menos uma especialização, obteve-se que a Ortodontia foi a especialidade mais frequente (27\%), seguida da 
Endodontia (18,9\%) e Periodontia com 15,3\% das especialidades citadas, como mostra a tabela a seguir:

Tabela 2 - Distribuição dos entrevistados quanto às especialidades.

\begin{tabular}{lll}
\hline & $\mathbf{n}$ & $\%$ \\
\hline Ortodontia & 30 & $27,0 \%$ \\
Endodontia & 21 & $18,9 \%$ \\
Periodontia & 17 & $15,4 \%$ \\
\hline Prótese & 10 & $9,0 \%$ \\
Implantodontia & 9 & $8,1 \%$ \\
\hline Dentística & 6 & $5,4 \%$ \\
Bucomaxilofacial & 5 & $4,5 \%$ \\
\hline Odontopediatria & 4 & $3,6 \%$ \\
Saúde da Família & 3 & $2,7 \%$ \\
\hline Estomatologia & 2 & $1,8 \%$ \\
\hline Saúde Coletiva & 2 & $1,8 \%$ \\
\hline Não especificou & 2 & $1,8 \%$ \\
\hline
\end{tabular}

Fonte: Dados da pesquisa.

Para a área de atuação, obteve-se que a maior parte $(39,0 \%)$ dos entrevistados afirmou atuar em consultório particular, 23,8\% em consultório e serviço público, 16,5\% apenas em serviço público e apenas 20 entrevistados (12,2\%) afirmou atuar em clínicas populares. Entre as diferentes áreas de atuação dos entrevistados, observou-se que em geral ocorre uma maior assertividades dos entrevistados que atuam nos consultórios particulares em relação aos demais tipos e combinações de atuação.

Quando questionados sobre o tempo decorrido do último curso de atualização sobre conhecimentos odontológicos frequentados, 59,1\% informaram o tempo de até 6 meses, $15,9 \%$ de 1 a 2 anos, 20,1\% informaram 2 anos ou mais e $4,9 \%$ se abstiveram de responder.

Sobre a participação de atualizações nas áreas da farmacologia ou terapêutica aplicada à odontologia, observou-se destaques para as respostas a respeito do meio para atualização foi: "Sigo protocolos rígidos e aplico os mesmos desde minha última formação" (39,6\%), "Leitura de artigos científicos" (25,6\%) e "Congressos ou simpósios" (15,9\%).

Em relação aos colutórios prescritos, foi possível observar que o Periogard® (Clorexidina) é o mais prescrito (74,8\%), seguido do Colgate Plax® (Triclosan) com 13,45\%, como mostra a Tabela 3: 
Tabela 3 - Colutórios prescritos e seus princípios ativos.

\begin{tabular}{|l|l|l|}
\hline & N & \% \\
\hline PERIOGARD® (Clorexidina) & 89 & $74,80 \%$ \\
\hline COLGATE PLAX® (Triclosan) & 16 & $13,45 \%$ \\
\hline CEPACOL® (Cloreto de Cetilpiridínio) & 6 & $5,05 \%$ \\
\hline LISTERINE® (Óleos Essenciais) & 3 & $2,55 \%$ \\
\hline PERIOTRAT® (Clorexidina) & 1 & $0,83 \%$ \\
\hline FLOGORAL® (Cloridrato de Benzidamida) & 1 & $0,83 \%$ \\
\hline CLOREXIDINA 2\%* & 1 & $0,83 \%$ \\
\hline CLOREXIDINA 0,012\%* & 1 & $0,83 \%$ \\
\hline CATAFLAN@ (Nimesulida)* & 1 & $0,83 \%$ \\
\hline Total & 119 & $100,0 \%$ \\
\hline Não prescrevem ou não souberem responder & 45 & \\
\hline
\end{tabular}

*Referente a prescrições inadequadas em relação a escolha do agente químico ou concentração. Fonte: Dados da pesquisa.

Dos colutórios prescritos, avaliou-se a correta correlação entre representante comercial e princípio ativo, onde obtevese $97,51 \%$ de respostas corretas e apenas 2,49\% incorretas. As prescrições com indicações corretas de marca comercial e princípio ativo foram as do Periogard, Colgate Plax, Cepacol, Listerine, Periotrat e Flogoral. Por outro lado, as prescrições de "clorexidina 2\%", "clorexidina 0,012\%" e "cataflan" foram classificadas como incorretas. De uma forma geral 70,73\% dos entrevistados prescreveram corretamente os colutórios, $1,8 \%$ não prescrevem corretamente, $25,67 \%$ não souberam responder e $1,8 \%$ não prescrevem nenhum tipo de colutório.

Em relação à prescrição de CLX, observou-se que 40,9\% dos entrevistados apresentaram prescrição correta, $28 \%$ apresentaram erro de posologia, 2,4\% apresentaram erro de dosagem, 7,3\% erro de dosagem e posologia, 15,9\% não souberam responder e apenas 5,5\% não prescrevem tal medicação. Ainda em relação à CLX e sua contraindicação do uso prolongado, foi possível perceber que $85,4 \%$ responderam corretamente, afirmando que o "uso limitado da Clorexidina por no máximo duas semanas se dá devido à possibilidade de ocorrer manchamento dental, alteração do paladar e indução a resistência bacteriana". Contra $12,2 \%$ de respostas incorretas e $2,4 \%$ que não souberam responder:

Ao serem questionados sobre quando usar agentes químicos como coadjuvantes na terapia periodontal, notou-se que grande parte dos entrevistados $(87,8 \%)$ respondeu corretamente, afirmando que "é preciso avaliar o caso antes para saber como e o quê prescrever", contra $11 \%$ de respostas incorretas e 1,2\% daqueles que não souberam responder.

Já em relação à prescrição de fitoterápicos como coadjuvante na terapia periodontal, dos que prescreveram $(8$ entrevistados), ocorreu igualdade quantitativa em cada substância prescrita. As prescrições corretas foram as de: Barbatimão, Própolis, Parodontax, Malvatricin, Extrato de Aroeira, Elixir Sanativo e Água Rabelo.

Das substâncias prescritas como fitoterápicos, apenas o METRONIDAZOL foi prescrito de maneira incorreta, pois não é um fitoterápico. E de uma forma geral, $87,2 \%$ dos entrevistados não prescrevem fitoterápicos como coadjuvante na terapia periodontal.

Quando questionados sobre qual agente anti-biofilme (contido em dentifrícios), de um modo geral 43,9\% dos entrevistados não souberam responder qual dentifrício atua como agente anti-biofilme, 38,4\% não prescrevem e apenas 17,7\% prescrevem corretamente $(\mathrm{n}=28)$ dentre os quais, 50\% citaram o "Colgate Total 12®", seguidos do "Prevent Anti-placa ${ }^{\circledR}$ " com 32,14\%, como mostra a Tabela 4, sendo todos eles prescritos de forma acertada para seu devido fim. 
Tabela 4 - Dentifrícios prescritos como agente anti-biofilme.

\begin{tabular}{|c|c|c|c|c|c|}
\hline & $\mathbf{N}$ & $\%$ & & & \\
\hline Não soube responder & 72 & $43,9 \%$ & & & \\
\hline Não prescreve & 63 & $38,4 \%$ & & & \\
\hline Prescreve corretamente & 28 & $17,7 \%$ & $\begin{array}{ll}\text { 1. } & \text { COLGATE TOTAL } \\
& \text { 12 }^{\circledR} \text { (triclosan) } \\
\text { 2. } & \text { PREVENT ANTI- } \\
\text { PLACA }^{\circledR} \text { (triclosan) } \\
\text { 3. } & \text { ORAL B ANTI- } \\
& \text { PLACA }{ }^{\circledR} \text { (Fluoreto de } \\
& \text { Estanho) } \\
\text { 4. } & \begin{array}{l}\text { NEUTRAÇÚCAR } \\
\text { (Bicarbonato de }\end{array} \\
& \text { Arginina) }\end{array}$ & $\begin{array}{l}3 \\
2\end{array}$ & $\begin{array}{l}10,71 \% \\
7,15 \%\end{array}$ \\
\hline Total & 164 & $100,0 \%$ & & & \\
\hline
\end{tabular}

Fonte: Dados da pesquisa.

Em detrimento ao tipo de dentifrício que é prescrito como agente anti-cálculo, 42,07\% dos entrevistados não prescrevem dentifrícios como agente anti-cálculo, 42,07\% não souberam responder e 15,86\% prescrevem corretamente, dentre os quais $38,4 \%$ afirmaram prescrever "Colgate Total 12®" como mostra a Tabela 5:

Tabela 5 - Dentifrícios prescritos como agente anti-cálculo.

\begin{tabular}{|c|c|c|c|c|c|}
\hline & $\mathbf{N}$ & $\%$ & & & \\
\hline Não soube responder & 69 & $42,07 \%$ & & & \\
\hline Não prescreve & 69 & $42,07 \%$ & & & \\
\hline Prescreve corretamente & 26 & $15,86 \%$ & 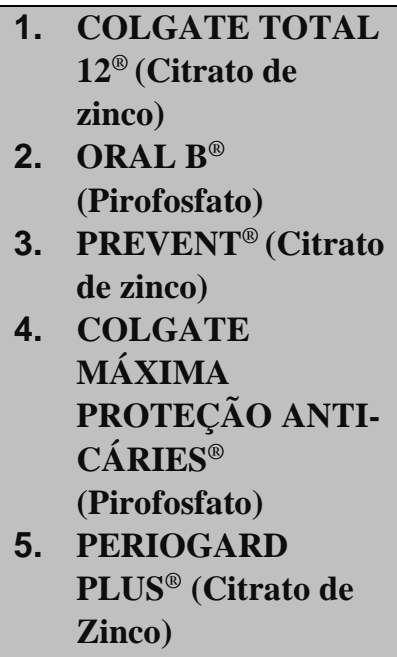 & $\begin{array}{l}9 \\
4\end{array}$ & $\begin{array}{l}34,6 \% \\
15,4 \%\end{array}$ \\
\hline Total & 164 & $100,0 \%$ & & & \\
\hline
\end{tabular}

Fonte: Dados da pesquisa.

Quando questionados sobre a substantividade de um agente químico, 72\% dos entrevistados fizeram a escolha da substância de forma correta marcando a alternativa que continha a "Clorexidina como agente de maior substantividade", 22,6\% marcaram de forma incorreta e 5,4\% não souberam responder a esta questão. 
Questionados se prescreviam o Cloreto de Cetilpiridínio (CCP), a maioria (88,4\%) afirmou não prescrever e apenas 6,7\% prescrevem. Dos entrevistados que afirmaram prescrever o Cloreto de Cetilpiridínio 45,4\% não especificaram a forma de prescrição, 27,3\% prescreveram de forma correta ( $3 x$ ao dia) e 27,3\% não prescrevem de forma correta (1 ou 2x ao dia).

Quando questionados sobre qual representante comercial de cada antimicrobiano contido em enxaguatórios bucais tinham conhecimento, foram observadas as seguintes porcentagens para as seguintes substâncias: sobre Cloreto de Cetilpiridínio 47\% souberam informar o representante comercial que continha tal substância, 3\% não acertaram e 50\% não souberam responder; sobre Óleos Essenciais 39,6\% acertaram, 0,6\% não acertaram e 59,8\% não souberam responder qual(is) representante(s) comercial(is) contêm óleos essenciais em sua composição; sobre Triclosan 45,1\% acertaram, 4,3\% não acertaram e 50,6\% não souberam responder; sobre Peróxido de Hidrogênio 28\% acertaram, 6,7\% não acertaram e 65,2\% não souberam responder; sobre a Clorexidina 79,3\% dos entrevistados responderam de forma correta quais enxaguatórios bucais contém tal substância, 1,2\% não acertaram e 19,5\% não souberam responder.

\section{Discussão}

O presente estudo apresenta como resultado que 39,6\% dos entrevistados não participam de atualizações nas áreas da farmacologia e terapêutica aplicada à odontologia, seguindo os mesmos protocolos desde a graduação. Porém alguns estudos têm mostrado a necessidade de atualizações da prática clínica, pois a abordagem baseada em evidência científica permite avaliar o conhecimento pela sua validade, influência e aplicabilidade, suprimindo a lacuna entre pesquisa e realidade dos serviços de saúde (Zina \& Moimaz, 2012; Brignardello-Petersen et al., 2014). A Odontologia Baseada em Evidência (OBE) é um novo conceito que, pela primeira vez, tenta sintetizar objetivamente todas as evidências científicas disponíveis para otimizar a eficácia e a eficiência da prática clínica (Damathé, Silva, Carli, Goiato \& Miyahara, 2012).

Além da necessidade de atualização periódica pelo volume de informações e pesquisas publicadas, é preciso saber identificar a hierarquia dos estudos, dando preferência aqueles que minimizam o risco de viés e que trazem evidências fortes de acordo com o método utilizado para alcançar seus achados (Brignardello-Petersen et al., 2014).

No que diz respeito à presente pesquisa se faz indispensável saber quais agentes químicos podem ser utilizados como adjuvantes para o controle mecânico do biofilme (Tartaglia, Tadakamadla, Connelly, Sforza \& Martin, 2019), já que alguns destes agentes podem proporcionar um benefício adicional significativo no controle do biofilme e de doenças periodontais (Brignardello-Petersen et al., 2014; Silva, et al., 2021). Atualmente o mercado brasileiro dispõe de uma variedade de produtos com agentes químicos para higiene bucal, assim como muitos ingredientes têm sido adicionados aos colutórios e dentifrícios tanto com a ação anti-biofilme quanto anti-cálculo (Damathé, Silva, Carli, Goiato \& Miyahara, 2012; Barbosa et al., 2017). De acordo com os achados desta pesquisa, os colutórios mais prescritos pelos entrevistados são os que contêm como princípio ativo Cloreto de Cetilpiridínio, Triclosan, Óleos Essenciais e Clorexidina.

O CCP faz parte dos componentes quaternários de amônia, que tem como sua principal característica o favorecimento na redução da adesão microbiana às superfícies dentais e aumento da permeabilidade da parede celular bacteriana culminando com a lise celular (Gonçalves et al., 2009; Sreenivasan et al., 2012). E apesar de alguns estudos como os de Amini, Araujo, Meimiau, Charles e Sharma (2009) e Sreenivasan et al. (2012) descreverem a eficácia do CCP uma porcentagem mínima de cirurgiões-dentistas alega prescrever CCP e a grande maioria afirmou não prescrevê-lo, e mesmo os que prescrevem ainda demonstram insegurança quanto a sua correta prescrição.

O TRI é um ingrediente comum em uma variedade de dentifrícios e enxaguatórios bucais, sua eficácia tem sido amplamente investigada demonstrando uma boa ação contra bactérias gram-positivas e negativas, sendo considerado um antimicrobiano de amplo espectro devido a sua capacidade de causar ruptura da membrana bacteriana de diversas espécies. Isoladamente possui efeito anti-biofilme moderado e por isso é associado ao Gantrez e Citrato de Zinco, pois estas substâncias 
potencializam seu efeito (Villalpando, Casarin, Pimentel, Cirano \& Casati, 2010; Costa, Amaral, Barbirato, Leão \& Fogacci, 2017). Contudo uma pequena porcentagem dos entrevistados $(13,4 \%)$ afirmou prescrever Colgate Plax ${ }^{\circledR}$ que contêm TRI como princípio ativo, o que pode levar ao entendimento de que poucos cirurgiões-dentistas sabem a respeito de sua eficácia e excelente aplicabilidade.

Bochechos contendo OEs estão entre as soluções antissépticas orais mais comercializadas devido à sua atividade antimicrobiana (Domingues, Oliveira, Costa, Silva, Nascimento \& Dietrich, 2021), capacidade de penetrar no biofilme e segurança inativação de enzimas, além de possuir também atividade anti-inflamatória (Gonçalves, Filho, Aragão, Segundo \& Lima, 2010). Em uma revisão sistemática Haas e colaboradores (2016) demonstraram que enxaguatórios bucais contendo OE utilizados como adjuvantes da higiene bucal mecânica são mais eficazes do que a higiene mecânica isolada. No entanto, dentre os entrevistados desta pesquisa que prescreveram algum tipo de colutório, apenas 2,55\% responderam que preconizam o uso de OEs para seus pacientes, o que pode ser indício de que se sabe pouco sobre os benefícios de tais substâncias.

A CLX é um dos antissépticos mais amplamente utilizados e investigados, com numerosos estudos estabelecendo sua segurança, estabilidade e eficácia na prevenção e controle da formação de biofilme, inibindo e reduzindo o desenvolvimento da gengivite. Possui uma ação antimicrobiana com duração de 12 horas sendo considerado esse período de elevada substantividade (Haas, Flores, Pelino \& Gatta, 2010; Zhang, Malik, McGrath \& Lam, 2018). Grande parte dos entrevistados (72\%) responderam de maneira correta que a CLX é a substância com maior substantividade.

Costa, Amaral, Barbirato, Leão e Fogacci (2017) afirmaram que pacientes com doença periodontal submetidos à terapia mecânica associada ao uso do enxaguatório bucal de CLX como adjuvante tiveram melhores resultados do que aqueles tratados apenas com terapia periodontal mecânica isolada. No entanto, deve-se avaliar o risco x benefício do uso da CLX em detrimento de seu possível efeito colateral (pigmentação extrínseca de dentes, restaurações e língua, descamação de mucosa bucal) (Gonçalves et al., 2009). De maneira geral 85,4\% dos entrevistados responderam corretamente, afirmando que o uso limitado da clorexidina se dá devido à possibilidade de ocorrer os efeitos adversos acima citados.

Para bochechos recomenda-se $15 \mathrm{ml}$ da solução de CLX a 0,12\% por 30 segundos, duas vezes ao dia, pela manhã e à noite após higiene bucal, segundo os fabricantes. O estudo clínico cruzado, duplo-cego de Sousa (2009) concluiu que a adoção de um intervalo de 30 minutos entre o emprego do dentifrício e a administração de solução de digluconato de clorexidina a $0,12 \%$ mostrou uma redução mais efetiva no índice de biofilme dental que o uso imediato do agente (Gonçalves, Filho, Aragão, Segundo \& Lima, 2010; Souza, Pochapski, Santos \& Pilatti, 2009; Zhang, Malik, McGrath \& Lam, 2018). Apesar de a CLX ser considerada padrão-ouro dos agentes químicos como coadjuvantes na terapia periodontal, esta pesquisa evidenciou que diante dos profissionais que prescreveram 48,06\% não o fazem corretamente que somando com a quantidade de entrevistados que não souberam responder $(15,9 \%)$, esse número ultrapassa a quantidade de entrevistados que prescreveram corretamente o agente químico, o que mostra que mesmo a CLX sendo uma das substâncias mais investigadas, muitos cirurgiões-dentistas não sabem sua correta prescrição.

Além das quatro substâncias mais prescritas, o presente estudo teve uma prescrição do Cloridrato de Benzidamina que é um agente anti-inflamatório utilizado para inflamação na cavidade oral que reduz significativamente o novo crescimento de biofilme dental e tem seu uso tópico na boca provado há muito tempo tanto para redução do biofilme como para tratamento de estomatites, síndrome da ardência bucal, dor de garganta e mucosite (Bozkurt, Ozturk \& Yetkin, 2005; Herrera et al., 2005). No entanto apenas $0,83 \%$ dos entrevistados faz uso de tal substância, implicando no desconhecimento de uma grande parte dos cirurgiões-dentistas a respeito de sua eficácia e diversas indicações.

O uso de produtos naturais na prevenção e tratamento de condições orais tem aumentado recentemente e pode ser benéfico para comunidades urbanas e rurais de baixo nível socioeconômico (Oliveira, Torres, Pereira, Mota \& Carlos, 2008). Poucos entrevistados alegaram prescrever fitoterápicos como coadjuvantes na terapia periodontal, e as substâncias citadas de 
forma correta foram: Barbatimão, Própolis, Parodontax (bicarbonato de sódio), Malvatricin, Extrato de Aroeira, Elixir Sanativo, Água Rabelo.

O objetivo dos agentes anti-biofilme e anti-gengivite é diminuir a inflamação gengival de modo que a doença periodontal destrutiva não se desenvolva ou tenha seu curso interrompido. Vários produtos anti-gengivite e anti-biofilme estão disponíveis comercialmente para os pacientes, e estes produtos são principalmente na forma de dentifrício ou enxaguatório bucal, onde a formulação adequada é importante tanto para manter a biodisponibilidade como para melhorar a substantividade (Andrade, Weidlich, Angst, Gomes \& Oppermann, 2015). Alguns agentes estão adicionados nos dentifrícios com funções terapêuticas como anti-biofilme e anti-cálculo. Ao serem questionados sobre a prescrição de dentifrícios como agente antibiofilme apenas 28 entrevistados afirmaram prescrever algum tipo de substância, e os princípios ativos de escolha se dividiram em Triclosan, Fluoreto de Estanho e Bicarbonato de Arginina. E 26 entrevistados prescrevem dentifrício anti-cálculo, com Citrato de Zinco e Pirofosfato como princípios ativos de suas composições. Essas prescrições demonstram que menos de 18\% do valor total da amostra sabem prescrever dentifrícios e identificar seu princípio ativo, o que mostra certo grau de desatualização em sua prática clínica por parte dos entrevistados sobre determinado tema.

Segundo a revisão sistemática de Alshehri (2018) um dentifrício contendo fluoreto estanhoso estabilizado é capaz de gerar redução no índice de inflamação e sangramento gengival, e o dentifrício que continha bicarbonato de sódio gerou redução no índice de biofilme dental. O ensaio clínico randomizado de Eilwood, Worthington, Blinkhorn, Volpe e Davies (1998) que avaliou a eficácia de um dentifrício contendo triclosan e copolímero concluiu que o uso não supervisionado de um creme dental com triclosan/copolímero pode reduzir significativamente o biofilme e a perda de inserção periodontal. Ainda que se tenham tantos estudos que embasam cientificamente o uso de diversas substâncias, faz-se necessário que os entrevistados tenham interesse em buscar dados que melhorem e atualizem sua prática clínica.

Segundo o estudo de Nascimento et al. (2009) tem-se também o bicarbonato de arginina como agente químico presente em dentifrícios, onde a quebra da arginina quando em meio bucal produz amônia, e essa produção pode influenciar positivamente o equilíbrio do PH da saliva e ajudar a prevenir o surgimento de uma microbiota patogênica no biofilme. E de acordo com uma única prescrição feita diante do número da amostra desta pesquisa, sugere-se o desconhecimento por parte de muitos entrevistados sobre essa substância.

Existem no mercado várias marcas de dentifrícios como agente anti-cálculo que têm como principal elemento o pirofosfato (Farias et al., 2011). Os resultados da metanálise de Gunsolley (2006) sugerem que para que se tenha uma boa condição gengival, os adultos devem adicionar um agente anti-placa, anti-gengivite ou anti-cálculo ao seu regime de higiene oral. Essa mesma metanálise avaliou as substâncias citrato de zinco e pirofosfato como agentes antimicrobianos usados em dentifrícios, afirmando que tais substâncias têm efeitos estatisticamente significativos. Mas somente 15,9\% dos entrevistados deste estudo souberam prescrever dentifrícios para controlar o cálculo supragengival de acordo com as evidências encontradas na literatura.

O estudo de Gonçalves e colaboradores (2010) demonstrou um baixo conhecimento na prescrição dos enxaguatórios bucais e também no conhecimento de sua composição, como a identificação do princípio ativo. E isso pode estar acontecendo devido a alguns fatores, como a falta de interesse por parte dos cirurgiões-dentistas em buscar tais informações, como pelo aumento no número de representantes comerciais disponíveis e as mudanças nas formulações e também por falha na formação acadêmica sobre o controle químico do biofilme dentário. E esses fatores podem levar os cirurgiões-dentistas a encontrarem dificuldade na correta prescrição dos agentes químicos como coadjuvantes na terapia periodontal (Azevedo, Ferreira, Pereira \& Lima, 2013; Carneiro et al., 2014). 


\section{Conclusão}

Os achados do presente estudo sugerem que o conhecimento dos cirurgiões-dentistas em relação à identificação das substâncias e reconhecimento das mesmas em seus representantes comerciais e que a prescrição de agentes terapêuticos para controle do biofilme dental é limitado. E essa restrição de conhecimento pode levar a prescrições incorretas tanto na escolha da substância como no tempo limite da terapia, sendo necessárias atualizações contínuas a respeito do tema para uma melhor prática da odontologia baseada em evidências científicas visto que as pesquisas sobre a contribuição dos agentes químicos como coadjuvantes no tratamento das doenças periodontais caminham a passos largos.

\section{Referências}

Alshehri, F. A. (2018). The use of mouthwash containing essential oils (LISTERINE_) to improve oral health: A systematic review. Saudi Dental Journal, 30, $2-6$.

Amini, P., Araujo, M. W. B., Mei-miau, W., Charles, C. A., \& Sharma, N. C. (2009). Comparative antiplaque and antigingivitis efficacy of three antiseptic mouthrinses: a two week randomized clinical trial. Braz Oral Res., 23(3), 319-325.

Andrade, E., Weidlich, P., Angst, P. D. M., Gomes, S. C. \& Oppermann, R. V. (2015). Efficacy of a triclosan formula in controlling early subgingival biofilm formation: a randomized trial. Braz Oral Res., 29(1), 1-8.

Araujo, D. B., Campos, E. J., Bastos, I. H. A., Paula, D. M., Tenório Junior, E. R. \& Araujo, R. P. C. (2012). Mouthrinses: active ingredients, pharmacological properties and indications. Revista Gaúcha de Odontologia, 60(3), 349-357.

Azevedo, E. P., Ferreira N. M. C., Pereira S. L. S. \& Lima, D. L. F. (2013). Informações dos fabricantes e representantes de produtos de higiene bucal sobre composição de enxaguatórios bucais. Perionews, 7, 588-592.

Barbosa, F. D. S. et al. (2017) Princípios ativos de enxaguatórios bucais comercializados em fortaleza, seus tipos e suas informações. Braz J Periodontol., 27(3), $07-15$

Bozkurt, F. Y., Ozturk, M. \& Yetkin, Z. (2005). The Effects of Three Oral Sprays on Plaque and Gingival Inflammation. J Periodontol., 76(10), 1645-1660.

Brignardello-Petersen, R. et al. (2014) A practical approach to evidence-based dentistry - How to search for evidence to inform clinical decisions. JADA, 145(12), 1262-1267.

Carneiro, S. D. R. M. et al. (2014) Identificação dos ingredientes ativos em enxaguatórios bucais, por cirurgiões-dentistas e acadêmicos. Perionews. 8, 470-414.

Charles, C. A. McGuir, J. A. Sharma, N. C. Qaqish, J. (2011). Comparative efficacy of two daily use mouthrinses: randomized clinical trial using an experimental gingivitis model. Braz Oral Res., 25(4), 338-344.

Cieplik, F. et al. (2019). Resistance Toward Chlorhexidine in Oral Bacteria - is there cause for concern? Frontiers in Microbiology, 10(587), 1-11.

Costa, L. F. N. P., Amaral, C. S. F., Barbirato, D. S. Leão, A. T. T. \& Fogacci, MF. (2017). Chlorhexidine mouthwash as an adjunct to mechanical therapy in chronic periodontitis - A meta-analysis. JADA, 1-11.Cieplik, F., Jakubovics, N. S., Buchalla, W., Maisch, T., Hellwig, E. \& Al-Ahmad, A. (2019). Resistance Toward Chlorhexidine in Oral Bacteria - is there cause for concern? Frontiers in Microbiology, 10(587), 1-11.

Demathé, A., Silva, A. R. S Carli, J. P, Goiato, M. C. \& Miyahara, G. I. (2012). Odontologia baseada em evidências: otimizando a prática e a pesquisa. RFO., $17(1), 96-100$.

Domingues, J. J., Oliveira, L. T. A., Costa, M. D. M. A., Silva, L. A. M., Nascimento, F., Dietrich, L. (2021). Uso de fitoterápicos e demais componentes vegetais e minerais na fabricação de produtos odontológicos naturais: Revisão de literatura. Research, Society and Development, 10(3), 1-10.

Eilwood, R. P., Worthington, H. V., Blinkhorn, A. S. B, Volpe, A. R. \& Davies R. M. (1998). Effeet of a triclosan/copolymer dentifrice on the incidence of periodontal attachment loss in adolescents J Ciin Periodontol., 25, 363-367.

Farias, B. C., et al. (2011). Redução do índice de cálculo supragengival: dentifrício anticálculo versus dentifrício convencional. R. Periodontia, 21(1), 49-54.

Filogônio, C. F. N., Soares, R. M., Horta, C. R, Penido, C. V. C. R. \& Cruz, R. A. (2011). Effect of vegetable oil (Brazil nut oil) and mineral oil (liquid petrolatum) on dental biofilm control. Braz Oral Res., 25(6), 556-61.

Goes, P. E. M., Lima, V. N., Carvalho, F. S. R., Queiroz, S. B. F., \& Camargo, I. B. (2013). Sialolito gigante em ducto de Wharton: um caso distinto e revisão da literatura. Rev. cir. traumatol. buco-maxilo-fac. 13(4), 81-88.

Gonçalves, E. M. et al. (2009). Investigação dos ingredientes ativos presentes nos colutórios e dentifrícios encontrados no mercado brasileiro. R. Periodontia, 19(1), 52-57.

Gonçalves, E. M., Filho, E. P. P., Aragão, P. R. C., Segundo, T. C. P. \& Lima, D. L. F. (2010). Grau de conhecimento dos cirurgiões-dentistas na prescrição de colutórios e dentifrícios. R. Periodontia, 20(4), 51-55.

Gunsolley, J. C. (2006) A meta-analysis of six-month studies of antiplaque and antigingivitis agents. The Journal of the American Dental Association. 37(12), 1649-1657. 
Haas, A. N. et al. (2016). Essential oils-containing mouthwashes for gingivitis and plaque: Meta-analyses and meta-regression. Journal of Dentistry, 1-9. Haas, A. N., Flores, M. F., Pelino, J. \& Gatta, A. D. (2010). Dental Students' Overall Knowledge Regarding Oral Antiseptics. R. Periodontia, 0(3), 47-52.

Herrera, D. et al. (2005). Efficacy of a $0.15 \%$ benzydamine hydrochloride and $0.05 \%$ cetylpyridinium chloride mouthrinse on 4 -day de novo plaque formation. J Clin Periodontol., 32, 595-603.

Miranda, S. L. F., Damaceno, J. T., Feveri, M., Figueiredo, L. C., Soares, G. M. S., Feres, M. \& Bueno-Silva, B. (2020). In Vitro Antimicrobial Effect of Cetylpyridinium Chloride on Complex Multispecies Subgingival Biofilm. Braz. Dent. J., 31(2), 103-108.

Nascimento, M. M., Gordan, V. V., Garvan, C. W., Browngardt, C. M. \& Burne RA. (2009). Correlations of oral bacterial arginine and urea catabolism with caries experience. Oral Microbiol Immunol., 24, 89-95.

Oliveira, S. M. A, Torres, T. C., Pereira, S; L; S., Mota, O. M. L. \& Carlos, M. X. (2008). Effect of a dentifrice containing Aloe Vera on plaque and gingivitis control. A double-blind clinical study in humans. J Appl Oral Sci., 16(4), 293-296.

Pannuti, C. M., Mattos, J. P., Ranoya, P. N., Jessus, A. M., Lotufo, R. F. M. \& Romito, GA. (2003). Clinical effect of a herbal dentifrice on the control of plaque and gingivitis. A double-blind study. Pesqui Odontol Bras., 17(4), 314-318.

Silva, A. F., Silva, E. T. C., Costa, S. R. R., Bezerra, P. L., Lourenço, A. H. A. \& Bernardino, I. M. (2021). O uso do aloe vera como coadjuvante no tratamento periodontal. Research, Society and Development, 10(1), 1-6.

Sousa, A. M., Pochapski, M. T., Santos, F. A. \& Pilatti, GL. (2009). Estudo clínico sobre a influência do dentifrício na efetividade da clorexidina no controle do biofilme dental. R. Periodontia, 19(1), 71-75.

Sreenivasan, P. K., Haraszthy, V. I. \& Zambon, J. J. (2012). Antimicrobial efficacy of 005\% cetylpyridinium chloride mouthrinses. Letters in Applied Microbiology, 56, 14-20.

Tartaglia, G. M., Tadakamadla, S. K., Connelly, S. T., Sforza, C. \& Martín, C. (2019). Adverse events associated with home use of mouthrinses: a systematic review. Ther Adv Drug Saf, 10, 1-29.

Villalpando, K. T., Casarin, R. C. V., Pimentel, S. P., Cirano, F. R. \& Casati, M. Z. (2010). A randomized clinical evaluation of Triclosan containing dentifrice and mouthwash association in the control of plaque and gingivitis. Quintessence International, 41(10), 855-861.

Zarandia, A., Salahaddin, S. \& Faramarzi, M. (2016). Efficacy of Different Concentrations of Chlorhexidine Mouthwash on Plaque Accumulation and Periodontal Parameters. Journal of Periodontology \& Implant Dentistry, 18(1), 8-11.

Zhang, J., Malik, N. A., McGrath, C. \& Lam, O. L. T. (2018). The effect of antiseptic oral sprays on dental plaque and gingival inflammation: A systematic review and meta-analysis. Int J Dent Hygiene, 1-11.

Zina, L. G. \& Moimaz, S. A. S. (2012). Odontologia baseada em evidência: etapas e métodos de uma revisão sistemática. Arq Odontol., 48(3), 188-199. 